\title{
AVALIAÇÃO CLÍNICA DE BOVINOS INOCULADOS COM VENENO DE Crotalus durissus terrificus DETOXIFICADO POR IODAÇÃO E IODAÇÃO COM ENCAPSULAÇÃO EM LIPOSOMAS
}

\author{
Luiz Alberto Lago ${ }^{1}$, Marilia Martins Melo ${ }^{1}$, Luis Guilherme Dias Heneine ${ }^{2}$, ERnani PaUlino \\ LAGO $^{3}$, NeIDE JUdith FARIA OlIVEIRA ${ }^{4}$, PAUlO GABRIEL PEREIRA SilVA JUNIOR ${ }^{5}$ \\ ${ }^{1}$ Professores Doutores da Universidade Federal de Minas Gerais, Belo Horizonte, MG, Brasil. lago@ vet.ufmg.br \\ ${ }^{2}$ Pesquisador Funed- Fundação Ezequiel Dias, Belo Horizonte, MG, Brasil \\ ${ }^{3}$ Professor Doutor da Universidade Federal de Viçosa, Viçosa, MG, Brasil \\ ${ }^{4}$ Professora Doutora do Instituto de Ciências Agrárias da Universidade Federal de Minas Gerais, Montes Claros, MG, Brasil \\ ${ }^{5}$ Professor Doutor da Faculdade de Estudos Administrativos de Minas Gerais, Belo Horizonte, MG, Brasil.
}

\begin{abstract}
Investigou-se a eficiência da detoxificação do veneno crotálico para bovinos, pelos métodos de iodação e iodação com encapsulação em liposomas, através da avaliação clínica dos animais inoculados. Onze fêmeas, com idade média de 18 meses e peso médio de $160 \mathrm{~kg}$, foram inoculadas com $0,03 \mathrm{mg} / \mathrm{kg}$ de peso vivo do veneno crotálico do tipo crotamina positivo. Cinco animais receberam o veneno iodado livre, cinco, o iodado encapsulado em liposomas e um animal recebeu o mesmo veneno na forma natural, para controle da letalidade da amostra. Avaliações clínicas foram realizadas a cada duas
\end{abstract}

horas após a inoculação do veneno $\left(\mathrm{T}_{0}-\mathrm{T}_{24}\right)$. Todos os parâmetros clínicos avaliados (comportamento, postura, temperatura, frequências respiratória, cardíaca e de movimentos de rumem, coloração de mucosas, funções sensorial e motora e alterações no local da inoculação) permaneceram dentro dos limites de normalidade desta espécie durante todo o período estudado. Conclui-se que a iodação do veneno crotálico, com ou sem incorporação em liposomas, suprime o quadro clínico do envenenamento crotálico nos bovinos.

PALAVRAS-CHAVE: bovino; Crotalus; veneno.

\section{CLINICAL EVALUATION OF CATTLE INOCULATED WITH Crotalus durissus terrificus SNAKE VENOM DETOXIFIED BY IODINATION WITH OR WITHOUT ENCAPSULATION INTO LIPOSOMES}

\section{ABSTRACT}

The efficacy of detoxification of the crotalic venom for cattle by iodination and iodination plus encapsulation methods was clinically evaluated. Eleven 18-month-old heifers, weighing $160 \mathrm{~kg}$ in average, were used in this study. Groups of five animals were inoculated intramuscularly with $0.03 \mathrm{mg} / \mathrm{kg}$ with either the detoxified non-encapsulated venom or the detoxified encapsulated venom. One control animal received the same dose of non-detoxified venom by the same route. Clinical evaluations were performed every two hours after venom inoculation $\left(\mathrm{T}_{0}-\mathrm{T}_{24}\right)$. All clinical parameters (behaviour, posture, temperature, cardiac, respiratory and rumen movements frequencies, color of mucous membrane, sensorial and motor functions, and alterations at the inoculation site) were within the normal standards of the species throughout the studied period. It could be concluded that iodination of the crotalic venom, with or without incorporation into liposomes, suppresses the clinical manifestations of the crotalic envenomation in cattle.

KEYWORDS: bovine; Crotalus; venom. 


\section{INTRODUÇÃO}

As serpentes do gênero Crotalus são responsáveis por $14 \%$ dos acidentes ofídicos em humanos no Brasil (NETTO et al. 2004) e provocam a maioria dos envenenamentos fatais (RANGEL-SANTOS et al. 2004). O tratamento desse envenenamento com soro heterólogo obtido de equinos hiperimunizados ainda é a opção disponível mais eficiente (CHOUMET et al. 1998); no entanto, ele causa, frequentemente, reações de hipersensibilidade no paciente humano tratado (NETTO et al. 2002) e provoca graves problemas na sua cadeia produtiva como alto custo orgânico e até mesmo a morte do animal soroprodutor, pois esse veneno é altamente tóxico e pouco imunogênico (CLISSA et al., 1999, FERREIRA JUNIOR et al., 2005). Além disso, apresenta ainda um alto custo na sua linha de produção (GUIDOLIN et al., 1989, FERREIRA JUNIOR et al., 2006).

Muitos estudos têm sido realizados com o objetivo de se encontrar alternativas para resolver esses problemas e a detoxificação do veneno com preservação da sua imunogenicidade parece ser importante passo nessa busca. KOCHOLATY et al. (1968) detoxificaram o veneno da cascavel sulamericana utilizando foto-oxidação e concluíram que, além da atenuação de seus efeitos deletérios, esse processo também preserva sua imunogenicidade. DANIEL et al. (1987) detoxificaram esse veneno mediante iodação controlada e concluíram que o método é eficiente para camundongos. FREITAS (1997) incorporou a crotoxina em liposomas e concluiu que houve redução de, pelo menos, 42 vezes na sua toxicidade.

Esse veneno é uma complexa mistura de peptídeos biologicamente ativos e proteínas com atividades enzimáticas, com capacidade de interferir em inúmeros processos fisiológicos, afetando órgãos e sistemas, causando manifestações clínicas graves e até morte (AZEVEDO-MARQUES et al., 1990; HUDELSON \& HUDELSON, 1995; RANGELSANTOS et al., 2004; LAGO et al., 2004). A crotoxina é o principal componente neurotóxico dessa mistura, molécula formada por duas subunidades, a crotapotina e a crotoxina $\mathrm{B}$, e é a principal causadora da sua letalidade (AIRD et al., 1985; AIRD et al., 1986, RANGEL-SANTOS et al., 2004, SAMPAIO et al., 2006).

Em humanos, o quadro clínico é típico de neuropatia, sendo observada, em alguns casos, a síndrome de rabdomiólise (MAGALHÃES et al., 1986; AMARAL et al., 1988). Os bovinos são mais sensíveis ao veneno da cascavel do que a maioria das outras espécies domésticas (BRASIL \& PESTANA, 1909). Eles sobrevivem se inoculados com $0,025 \mathrm{mg} / \mathrm{kg}$ do veneno, via intramuscular (ARAUJO et al.1963), e morrem em 28 horas se a dose inoculada for de $0,03 \mathrm{mg}$, apresentando um quadro clínico característico de neuropatia com incoordenação motora, tremores musculares e paralisia flácida, contudo, sem alterações significativas na frequência respiratória e na temperatura retal (LAGO et al., 2000).

SOERENSEN et al. (1995) inocularam bovinos com veneno crotálico e observaram que os animais apresentaram incoordenação motora, paralisia do posterior e morte em 24 horas. Os autores concluíram que a temperatura, frequência respiratória, frequência cardíaca e frequência de movimentos de ruminação não são parâmetros de diferenciação clínica e que o edema, nesse caso, é notoriamente inferior ao causado pelo veneno botrópico.

O objetivo deste trabalho foi avaliar a eficiência da detoxicação do veneno da Crotalus durissus terrificus para bovinos, pelos métodos de iodação e iodação com encapsulação em liposomas, por meio da avaliação clínica, para subsidiar estudos de imunogenicidade deste veneno nesta espécie.

\section{MATERIAL E MÉTODOS}

$\mathrm{O}$ experimento foi realizado em abril de 2001 e foram utilizadas 11 novilhas mestiças, com idade média de 18 meses e peso médio de $160 \mathrm{~kg}$. Os animais foram mantidos em baias, identificados, vermifugados com albendazole ${ }^{1} \mathrm{e}$ banhados com solução de amitraz ${ }^{2}$, segundo recomendação do fabricante, no dia seguinte ao de sua chegada ao hospital veterinário. Foram formados três grupos experimentais: no Grupo VI $(n=5)$, os animais receberam inoculação com veneno iodado livre; no Grupo VILP $(n=5)$, inoculação com veneno iodado incorporado em liposomas; no Grupo V, um animal recebeu a inoculação com veneno na forma natural, para verificação da letalidade (controle).

O veneno utilizado foi o crotálico do tipo crotamina positivo, fornecido pelo Centro de Pesquisa e Desenvolvimento da Fundação Ezequiel Dias (FUNED) que foi diluído em

\footnotetext{
${ }^{1}$ Valbazen-SmithKline

2 Triatox-Mallinckrodt
} 
solução salina $0,85 \%$ e fracionado em duas alíquotas. A primeira alíquota, na concentração de $5,00 \mathrm{mg} / \mathrm{ml}$, foi inoculada no animal do Grupo V e a segunda, submetida à iodação, segundo HENEINE et al. (1986), foi subdividida em duas frações: a primeira, na concentração de $8,39 \mathrm{mg} / \mathrm{ml}$, foi inoculada nos animais do Grupo VI e a segunda, na concentração de $6,00 \mathrm{mg} / \mathrm{mL}$, submetida ao processo de incorporação do veneno em liposomas, segundo FREITAS et al. (1997), foi inoculada nos animais do Grupo VILP. A inoculação do veneno, na dose de $0,03 \mathrm{mg} / \mathrm{kg}$, foi feita por via intramuscular, na região glútea, conforme BELLUOMINI (1972).

Antes da inoculação do veneno (tempo zero) e a cada duas horas, durante 24 horas $\left(\mathrm{T}_{2}\right.$ a $\mathrm{T}_{24}$ ), foram realizados exames clínicos e colheita de sangue venoso da jugular em tubos venoject ${ }^{3}$. Foi definido um protocolo de exame clínico com avaliação do comportamento e da postura, medição da temperatura retal, frequências respiratória, cardíaca e de movimentos de rumem, coloração de mucosas, avaliação das funções sensorial e motora e de alterações no local da inoculação. A concentração do veneno no soro sanguíneo dos animais foi determinada por teste imunoenzimático (ELISA), segundo HENEINE et al. (1990). O animal do Grupo V foi necropsiado e os fragmentos de órgãos colhidos foram conservados em formol a $10 \%$ e em seguida, processados e corados pela hematoxilina-eosina, segundo LUNA (1968). O delineamento experimental foi um sistema de "blocos ao acaso", em que cada animal configurou um bloco, destacando-se $\quad \mathrm{o} \quad \mathrm{T}_{0}$ como sendo $\mathrm{o}$ controle experimental (cada animal é controle absoluto e perfeito de si mesmo, SNEDECOR \& COCHRAM, 1967). Análise de variância e os testes de Kruskal-Wallis e de Scott-Knott, foram usados para verificação das diferenças entre as médias.

Este trabalho não foi submetido à Comissão de Ética de Experimentação Animal por ser anterior à Lei 11.794/08 da Constituição Federal que regulamenta e estabelece procedimentos para o uso científico de animais. Trata-se de dados experimentais de banco de teses, cujo experimento foi realizado no mês de abril de 2001 e seu projeto de pesquisa devidamente aprovado e registrado pela Escola de Veterinária da Universidade Federal de Minas Gerais no ano de 1998; portanto, num período em que não havia Comissão de Ética e Experimentação Animal (CETEA) nesta instituição.

\footnotetext{
${ }^{3}$ Terumo Medical Corporation
}

\section{RESULTADOS}

A Figura 1 ilustra o perfil da concentração do veneno crotálico na circulação dos animais utilizados no experimento. O grupo tratado com veneno iodado (VI) apresentou uma concentração de veneno mais elevada e com oscilações maiores durante todo o período estudado. O grupo tratado com veneno iodado encapsulado em liposomas (VILP) apresentou um perfil com concentração baixa, mas bastante estável durante todo tempo. Todos os grupos mostraram aumentos entre duas e 4 horas após, sendo mais altos e o mais rápidos no Grupo VI. Embora a diferença de concentração entre os Grupos VI e VILP seja grande, o perfil apresentado é muito semelhante, com três picos observados em três, 11 e 18 horas após o envenenamento. $\mathrm{O}$ Grupo $\mathrm{V}$ apresentou uma concentração máxima em quatro horas, caindo a valores em torno de $1,0 \mathrm{ng} / \mathrm{mL}$ em oito horas e assim permanecendo até a morte do animal.

As Figuras 2 e 3 ilustram os perfis da temperatura, frequências respiratória, cardíaca e de movimentos ruminais dos animais utilizados no experimento. Houve diferenças estatísticas significativas entre os tempos $\mathrm{T}_{4,6,8,10}, \mathrm{~T}_{0,2,12}, \mathrm{~T}_{14}$,

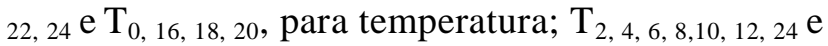

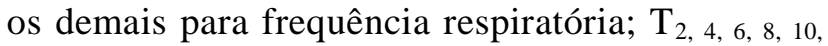
${ }_{12}, \mathrm{~T}_{14,16,22,24} \mathrm{e} \mathrm{T}_{0,18,20}$, para frequência cardíaca entre os Grupos VI e VILP; contudo, os valores permaneceram dentro dos limites de normalidade da espécie. O animal do Grupo V apresentou em $\mathrm{T}_{20}$ diminuição da frequência respiratória, acompanhada de dispnéia, sialorréia seguida de morte 21 horas após envenenamento. Os animais dos Grupos VI e VILP apresentaram discreta inapetência, que desapareceu após o período experimental e não foram observadas alterações dos outros parâmetros clínicos estudados.

$\mathrm{O}$ animal do Grupo V apresentou quadro clínico típico do envenenamento crotálico conforme descrito por SOERENSEN et al. (1995) e também LAGO et al. (2000) pois, logo após a inoculação, já apresentou inquietação e desconforto e após duas horas observou-se apatia com cabeça baixa, letargia e edemaciação discreta no local da inoculação. Dez horas após a inoculação o edema já havia desaparecido e diminuição da sensibilidade superficial, do tônus muscular, do reflexo patelar, com incoordenação motora e decúbito external foram observados. Decorridas 16 horas da inoculação o animal apresentou paralisia flácida dos membros pélvicos e, ao completar 20 horas, surgiram dispnéia e 
sialorréia, culminando com a morte passadas vinte e uma horas desde o envenenamento.

$\mathrm{O}$ estudo anatomo-histopatológico desse animal revelou lesões discretas como pequenas áreas hemorrágicas do tipo sufusões e petéquias na musculatura esquelética e cardíaca, degenerações hialina, vacuolizações e estriações nas fibras musculares e infiltrados de células polimorfonucleares, principalmente no local da inoculação do veneno.

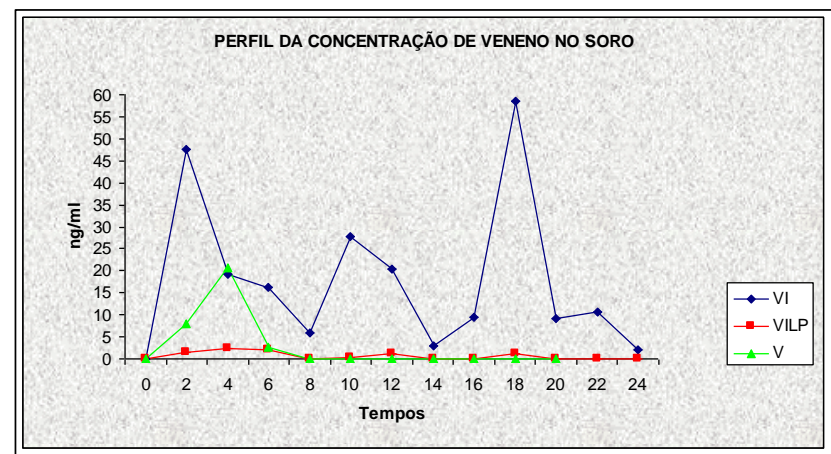

Fig.1. Perfil da concentração de veneno no soro de bovinos submetidos à inoculação com veneno crotálico iodado livre (VI), iodado encapsulado em liposomas (VILP) e veneno natural (V).
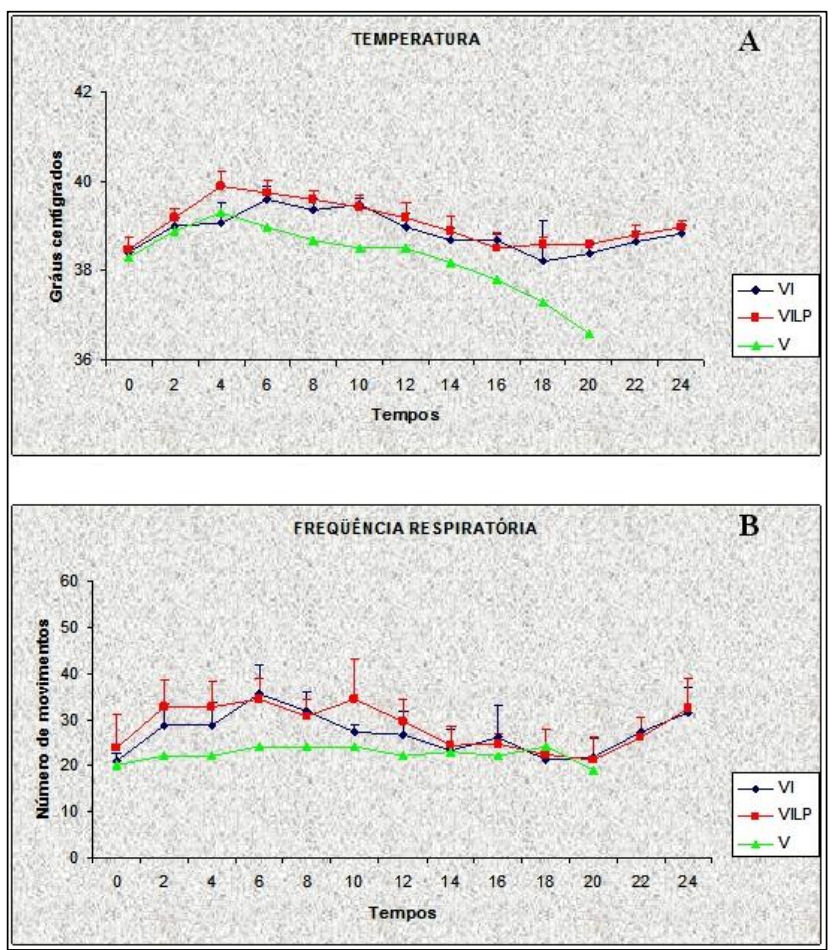

Fig.2. Perfil de parâmetros clínicos de bovinos submetidos à inoculação com veneno crotálico iodado livre (VI), iodado encapsulado em liposomas $(\mathrm{VILP})$ e veneno natural $(\mathrm{V}) . \mathrm{A}=$ Temperatura; $\mathrm{B}=$ Frequência respiratória.

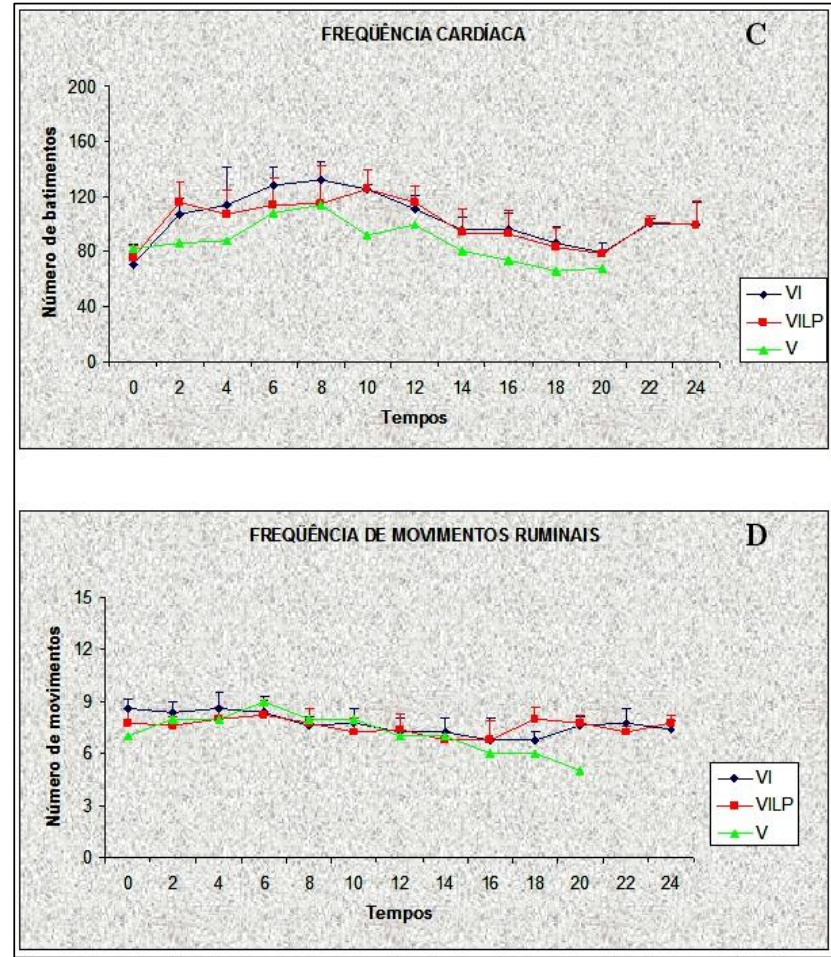

Fig.3. Perfil de alguns parâmetros clínicos de bovinos submetidos à inoculação com veneno crotálico iodado livre (VI), iodado encapsulado em liposomas (VILP) e veneno natural (V). $\mathrm{C}=$ Frequiência Cardíaca; $\mathrm{D}=$ Frequência de movimentos ruminais.

\section{DISCUSSÃO}

A estabilidade e baixa concentração de veneno no soro apresentada pelo Grupo VILP ocorreram, principalmente, porque uma das propriedades dos liposomas é exatamente permitir que $o$ veneno seja liberado mais lentamente, portanto, em quantidades menores e mais constantes (FREITAS \& FREZARD, 1997). Nisso consiste um dos principais efeitos imunoadjuvantes dos liposomas.

As maiores médias da temperatura $\mathrm{e}$ frequências respiratória e cardíaca observadas nos tempos entre $\mathrm{T}_{2}$ e $\mathrm{T}_{12}$ e no tempo $\mathrm{T}_{24}$ ocorreram possivelmente porque essas medições começaram às nove horas, logo, os cinco tempos seguintes e o $\mathrm{T}_{24}$, coincidiram com o período mais quente do dia. Além disso, outro fator que possivelmente contribuiu para essa discreta hipertermia é o fato de que os animais estavam alojados num galpão cujo teto é de amianto e com ventilação deficiente. O esforço físico dos animais a cada colheita de material, durante sua contenção, também contribuíram para a elevação de 
temperatura observada. A eliminação de calor via respiratória, vasodilatação periférica e elevação da frequência cardíaca fazem parte do mecanismo fisiológico de termólise (SILVA, 2000; STARLING et al., 2002).

A observação de valores de temperatura do Grupo VILP, discretamente superiores, ocorreu provavelmente devido aos liposomas, por meio de seu efeito imunoadjuvante de liberação lenta e em menores quantidades do veneno e do processo inflamatório provocado pela sua presença. A síndrome febril pode estar presente no quadro clínico do acidente ofídico crotálico segundo HUDELSON \& HUDELSON (1995).

Casos relatados por AMARAL et al. (1988) apresentaram temperatura sem alteração. SOERENSEN et al. (1995) investigaram o quadro clínico do envenenamento crotálico e botrópico bovino e concluíram que temperatura, frequiência respiratória e frequência cardíaca não são parâmetros de diferenciação clínica entre esses envenenamentos. LAGO et al. (2000) observaram que a temperatura e a frequência respiratória dos animais inoculados com esse veneno mantiveram-se normais até 20 horas desde o envenenamento, quando começaram a cair.

Embora a frequência respiratória tenha se elevado nos Grupos VI e VILP, dispnéia foi observada apenas no animal do Grupo V. Diversos autores relatam dispnéia nesse envenenamento em humanos (MAGALHÃES et al., 1986; AZEVEDOMARQUES et al., 1990; JORGE \& RIBEIRO, 1992, LAGO et al., 2000; e LAGO et al., 2004). A discreta inapetência apresentada pelos animais dos Grupos VI e VILP provavelmente decorreu do estado de desconforto e manipulação a cada duas horas a que foram submetidos.

\section{CONCLUSÃO}

De acordo com os resultados observados neste trabalho, conclui-se que a iodação com ou sem encapsulação em liposomas suprime completamente o quadro clínico do envenenamento crotálico em bovinos e, portanto, a metodologia de detoxificação do veneno utilizado mostrou-se eficiente. Diante disso, fica evidente a necessidade da realização de estudos da imunogenicidade do veneno detoxificado por esse método.

\section{REFERÊNCIAS}

AIRD S.D., KAISER I.L., LEWIS R.V. \& WILLIAM

G.K.. Rattlesnake presynaptic neurotoxins: primary structure and evolutionary origin of the acidic subunit. Biochemistry, v.24, n.25, p.7054-7058. 1985

AIRD S.D., KAISER I.L., LEWIS R.V. \& WILLIAM G.K.. A complete amino acid sequence for the basic subunit of cro. Archives of Biochemistry and Biophysics, v.249, n.2, p. 296-300. 1986

AMARAL C.F.S., RESENDE N.A., PEDROSA T.G., PEDROSO E.R.P.. Afibrinogenemia secundária a acidente ofídico crotálico (Crotallus durissus terrificus). Revista do Instituto de Medicina Tropical de São Paulo, v.28, n. 4 , p.228-233. 1988

ARAUJO P., ROSENFELD G. \& BELLUOMINI H.E. Toxicidade de venenos ofídicos. II. Doses mortais para bovinos. Arquivos do Instituto Biológico, v. 30, p.43-51. 1963

AZEVEDO-MARQUES M.M., CUPO P., AMARAL C.F.S. \& HERING S. Rattlesnake bites: Clinical features and complementary tests. Memórias do Instituto Butantan, v. 52, Supl., p.27-30. 1990

BELLUOMINI H.E. Ensaios soroterápicos no envenenamento crotálico experimental em bovinos. Tese de Doutorado, Instituto de Ciências Biomédicas, USP, São Paulo. 1972

BRASIL V. \& PESTANA B.R. Nova contribuição ao estudo do envenenamento ophidico. V. Ação phisiologica. Revista de Medicina de São Paulo, v.12, p.415425.1909

CHOUMET V., LAFAYE P., MAZIE J. C. \& BON C. A monoclonal antibody directed against the no-toxic subunit of a dimeric phospholipase A2 neurotoxin, crotoxina, neutralizes its toxicity. Biological Chemistry, v.379, p.899-906. 1998

CLISSA P.B., NASCIMENTO N. \& ROGERO J.R. Toxicity and immunogenicity of Crotalus durissus terrificus venom treated with different doses of gamma rays. Toxicon, v.37, p.1131-1141. 1999

DANIEL, J.P., HENEINE, L.G.D., TAVARES, C.A.P., NASCIMENTO, M.C.S., HENEINE, I.F. Generation of protective immune sera by Crotalus durissus terrificus venom detoxified by controlled iodination. Brasilian Journal of Medical and Biological Research, v. 20, p. 713-720. 1987

FREITAS T.V. \& FREZARD F. Encapsulation of native crotoxin in liposomes: A safe approach for the production of antivenom and vaccination against Crotalus durissus terrificus venom. Toxicon, v.35, n.1, p.91-100. 1997

FERREIRA JUNIOR R.S., NASCIMENTO N., MARTINEZ J.C., ALVES J. B., MEIRA D. A. \& BARRAVIERA B. Immunization with native and cobalt 60-irradiated Crotalus durissus terrificus venom in Swiss mice: Assessment of the neutralizing potency of antisera. Journal of Venomous and Animals Toxins including Tropical Diseases, v.11, n.3, p.299-314. 2005

FERREIRA JUNIOR R.S., NASCIMENTO N., COUTO R., ALVES J.B., MEIRA D.A. \& BARRAVIERA B. 
Laboratory evaluation of young ovines inoculated with natural and ${ }^{60} \mathrm{Co}$-irradiated Crotalus durissus terrificus venom during hyperimmunization process. Journal of Venomous and Animals Toxins including Tropical Diseases, v.12, n.4, p.620-631. 2006

GUIDOLIN R., DIAS DA SILVA W., HIGASHI H.G., CARICATTI C.P., LIMA M.L.S.R. \& MARCELINO J.R. 1989. Hiperimunização de cavalos soroprodutores com venenos botrópico e crotálico tratados por glutaraldeido. Memórias do Instituto Butantan, v.51, p.85-90. 1989

HENEINE L.G.D., CARDOSO V.N., DANIEL J.P. \& HENEINE F.I. Detoxification of the $\mathrm{T}_{2}$ fraction from a scorpion (Tityus serrulatus, Lutz et Mello) venom by iodination and some immunogenic properties of the derivatives. Toxicon, v.24, n.5, p.501-505. 1986

HENEINE L.G.D., CATTY D. \& THEAKSTON R.D.G. Development of a species-specific ELISA for Brazilian pit-viper venoms. Brazilian Journal of Medical and Biological Research, v.23, p.585-588. 1990

HUDELSON S. \& HUDELSON P. Pathophysiology of snake envenomization and evaluation of treatments. Part III. Compendium on Continuing Education for the Practicing Veterinariam, v.17, n.11, p.1385-1394. 1995

JORGE M.T. \& RIBEIRO L.A. Epidemiologia e quadro clínico do acidente por cascavel Sul-Americana (Crotalus durissus). Revista do Instituto de Medicina Tropical de São Paulo, v.34, n.4, p.347-354. 1992

KOCHOLATY W.F., GOETZ C.S., ASHLEY D.B., BILLINGS T.A. \& LEDFORD E.B. Immunogenic response of the venoms of fer-de-lance, Bothrops atrox asper, la cascavella, Crotalus durissus terrificus following photooxidative detoxification. Toxicon, v.5, p.153-158. 1968

LAGO L.A., FERREIRA P.M., FACURY FILHO E.J., MELO M.M. \& ALZAMORA FILHO F. Quadro clínico do envenenamento crotálico experimental em bovinos (Crotalus durissus terrificus, crotamina positivo). Brazilian Journal Veterinary Research Animal Science, v.3, n.4, p.312-315. 2000

LAGO L. A. ; MARQUES JÚNIOR, A. P. ; MELO, M. M. ; LAGO, E. P. ; OLIVEIRA, N. J. F. ; ALZAMORA FILHO, F. Perfil bioquímico sorológico de bovinos inoculados experimentalmente com veneno crotálico iodado livre e iodado incorporado em lipossomas. Arquivo Brasileiro de Medicina Veterinária e Zootecnia, v. 56, n. 5, p. 653-657. 2004

LUNA L.G. Manual of Histologic Staining Methods of the Armed Force Institute of Pathology. 3rd ed. McGraw Hill, New York. 1968
MAGALHÃES R.A., RIBEIRO M.M.F., RESENDE N.A. \& AMARAL C.F.S. Rabdomiólise secundária a acidente ofídico crotálico (Crotalus durissus terrificus). Revista do Instituto de Medicina Tropical de São Paulo, v.28, n.4, p.228-233. 1986

NETTO D.P., CHIACCHIO S.B., BICUDO P.L., BICUDO P. L., ALFIERE A. A. \& NASCIMENTO N. Humoral response and neutralization capacity of sheep serum inoculated with natural and cobalt $60^{-}$-irradiated Crotalus durissus terrificus venom (Laurenti, 1768). Journal Of Venomous and Animals Toxins, v.8, n.2, p.1-11. 2002

NETTO D.P., CHIACCHIO S.B., BICUDO P.L., ALFIERE A.A., BALARIM M. \& NASCIMENTO N. Hematological changes in sheep inoculated with natural and cobalt ${ }_{60}$-irradiated Crotalus durissus terrificus venom (Laurenti, 1768). Journal Of Venomous and Animals Toxins including Tropical Diseases, v.10, n.1, p.34-52. 2004

RANGEL-SANTOS A., LIMA C., LOPES-FERREIRA M. \& CARDOSO D.F. Immunosupressive role of principal toxin (crotoxin) of Crotalus durissus terrificus venom. Toxicon, v.44, p.609-616. 2004

SAMPAIO S.C., SANTOS M.F., COSTA E.P., RANGEL-SANTOS A., CARNEIRO S.M., CURI R. \& CURY Y. Crotoxin induces actin reorganization and inhibits tyrosine phosphorylation and activity of small GTPases in rat macrophages. Toxicon, v.47, p.909-919. 2006

SILVA, R.G. Introdução à bioclimatologia animal. 1.ed. SãoPaulo: Nobel, 286p. 2000

SNEDECOR G.M. \& COCHRAM W.G. Statiscal Methods. 6th ed. Iowa State University Press, Ames. 580p. 1967

SOERENSEN B., BARROS A.R., NETO L.Z., OLIVEIRA A.M., SANTOS R.V., MESSIAS C.V., SILVA A.R.C., CAPOSSOLI E.A., CAVALCANTE N.B.C., VELLUCCI S.C.C., REPETTI E., SANTOS P.C.G., PACCHINI C.E. \& JUNIOR M.A. Aspecto clínico e laboratorial do envenenamento botrópico e crotálico em bovinos. Unimar Ciências, v.4, n.2, p.2833. 1995

STARLING J. M. C., SILVA. R. G., MUÑOZ, M. C., BARBOSA, G. S. S. C., PARANHOS DA COSTA, M. J. R. Análise de Algumas Variáveis Fisiológicas para Avaliação do Grau de Adaptação de Ovinos Submetidos ao Estresse por Calor. Revista Brasileira de Zootecnia, v.31, n.5, p.2070-2077, 2002.

Protocolado em: 07 out. 2009. Aceito em: 09 abr. 2012. 